\title{
Information as Influence: How Institutions Mediate the Impact of Scientific Assessments on Global Environmental Affairs
}

\section{Citation}

Clark, William C., Ronald Mitchell, David Cash, Frank Alcock. 2002. Information as Influence: How Institutions Mediate the Impact of Scientific Assessments on Global Environmental Affairs. KSG Working Papers Series, RWP02-44.

\section{Published Version}

http://www.belfercenter.org/sites/default/files/legacy/files/rwp02_044_clark.pdf

\section{Permanent link}

http://nrs.harvard.edu/urn-3:HUL.InstRepos:32696189

\section{Terms of Use}

This article was downloaded from Harvard University's DASH repository, and is made available under the terms and conditions applicable to Other Posted Material, as set forth at http:// nrs.harvard.edu/urn-3:HUL.InstRepos:dash.current.terms-of-use\#LAA

\section{Share Your Story}

The Harvard community has made this article openly available.

Please share how this access benefits you. Submit a story.

\section{Accessibility}




\title{
John F. Kennedy School of Government Harvard University Faculty Research Working Papers Series
}

\author{
Information as Influence: \\ How institutions mediate the impact of \\ scientific assessments on global environmental \\ affairs
William Clark, Ronald Mitchell, David Cash, and Frank Alcock

November 2002

RWP02-044
This paper can be downloaded without charge from the Social Science Research Network at: http://ssrn.com/abstract_id=357521

The views expressed in the KSG Faculty Research Working Paper Series are those of the author(s) and do not necessarily reflect those of the John F. Kennedy School of Government or Harvard University. All works posted here are owned and copyrighted by the author(s). Papers may be downloaded for personal use only. 


\title{
INFORMATION AS INFLUENCE:
}

\section{HOW INSTITUTIONS MEDIATE THE IMPACT OF SCIENTIFIC}

\author{
ASSESSMENTS ON GLOBAL ENVIRONMENTAL AFFAIRS ${ }^{1}$ \\ William Clark, Ronald Mitchell, David Cash, ANd Frank Alcock ${ }^{*}$
}

\section{INTRODUCTION}

Knowledge in general, and the global flow of information in particular, have become increasingly important forces shaping the course of world affairs (Keohane and Nye 1998; World Bank 1999; Sachs 2000). The powerful role of technology in driving economic growth has been recognized since at least the work of Solow (1956). Technical information, in the form of both factual knowledge about the state of the world and causal theories about how it works, is increasingly called upon to guide tasks ranging from verifying nuclear testing treaties, to planning structural adjustment policies for struggling economies, to managing international fisheries. A belief in the potential power of information has led to calls for improved transparency of information flows in all manner of global governance regimes (Finel and Lord 2000; Goldring 1993; Mitchell 1998; Müller 1994; United Nations and Department for Disarmament Affairs 1992).

\footnotetext{
* William C. Clark, David Cash and Frank Alcock are at the John F. Kennedy School of Government,
} Harvard University, 79 Kennedy Street, Cambridge MA 02138 USA. Ronald B. Mitchell is with the Department of Political Science, University of Oregon, Eugene OR 97403. Correspondence should be addressed to William Clark at the above address or via email at William_clark@harvard.edu. 
But the general recognition that information matters in world affairs has not led to agreement on when, how, and under what conditions it influences the behavior of policy actors. Some progress has been made in understanding the role of information in arms control and macro-economic policy where a relatively few powerful state actors often dominate the scene (Goldstein and Keohane 1993). But the tasks of governance in today's world are increasingly complex and interdependent, with important roles played not only by state governments, but also by private sector and nongovernmental actors as well as governments at both sub- and suprastate scales (Keohane and Nye 1998). Despite the vast and growing array of institutions involved in collecting, analyzing, and disseminating information potentially relevant to global governance, our understanding of the role that these "information institutions" play in world affairs remains limited (Nye and Donohue, 2000). In the absence of such understanding, efforts to improve the institutional arrangements for harnessing knowledge to address global problems will remain - at best - inefficient exercises in "muddling through." In this paper we seek to contribute some of the needed understanding through a discussion of how institutions mediate the impact of scientific assessments on global environmental affairs. The discussion is based upon a larger research agenda that seeks to better connect knowledge to action in the area of sustainable development (Kates et al., 2001; http://sust.harvard.edu/; http://sustainabilityscience.org ).

Although information plays important, if different, roles in an array of global issue areas, we focus here on global environmental affairs. They are important in their own right and, in addition, they provide a rich set of cases for analyzing the interplay of technical knowledge and public policy. Environmental problems are typical of the complex, interdependent challenges facing today's world. Ranging from climate change to trade in hazardous materials to the 
management of fisheries, they are characterized by a multiplicity of actors, by limited power of individual actors to impose their will on others, and by multiple linkages to other issue areas. Many environmental problems involve spatial scales that require international coordination for their resolution. Yet, the location-specific characteristics of both environmental impacts and management mean that effective responses require integration across global, regional and local levels of governance (Cash 2001; Young 1994). Finally, we focus on environmental "affairs" rather than "policy" to emphasize how information affects not just the behaviors of governments, but also the larger field of interactions among government groups, private firms, third sector advocacy groups, and scientists that together constitute society's grappling with environmental problems (Social Learning Group 2001a; Social Learning Group 2001b; Fritz, 2000).

Our focus on scientific assessments as opposed to knowledge or information in general also requires comment. People making decisions about what to do and how to do it have always sought to inform their own choices and influence the behavior of others with information from private advisors, public polls, and market prices to military intelligence, news media, advertising, and propaganda. Recently, "scientific" information in particular has become a basis for making and defending public choices in policy contexts. In part, this reflects a widely shared (if hardly universal) belief that information derived from scientific research is - other things being equal more likely to be reliable and instrumentally effective for certain purposes than information based on personal opinion, political ideology, or other sources. In part, it reflects efforts by leaders to show that their policy positions are not merely pursuit of self-interest but constitute an objectively defensible means for achieving agreed upon public ends (Ezrahi 1967). Finally, the increasing demand for scientific advice has created a supply of advisors and advisory organizations that have, in turn, advocated for wider use of their skills and products (Price 1983). 
Not surprisingly, there is often considerable contention regarding the "scientificness" of particular bodies of information, including that information's implications, authoritativeness, expected influence, and disinterestedness in particular situations.

Formal "assessments" - such as the reports of the Intergovernmental Panel on Climate Change (IPCC), the World Meteorological Organization's ozone assessments, and the Global Biodiversity Assessment - have arisen as organized efforts to harness scientifically-grounded information to inform environmental policy making in the face of controversy. Such assessments usually draw from natural and/or social sciences research to produce information about the current state of the world, past trends and future forecasts of that state, and inferences about the human and non-human factors and processes that cause change in the state of the world. They may also include analysis of the likely effects of alternative policies to resolve, mitigate, or respond to a given problem. The production of such assessments has become a major activity of the global scientific community, with many of the world's over 200 multilateral environmental agreements requiring periodic assessments to support their implementation and revision. Although most of these assessments use fewer resources than the IPCC - its Third Report involved thousands of authors and reviewers - the scientific community makes a substantial investment in their production, review and dissemination.

Earlier efforts have shown that formal scientific assessments sometimes have demonstrable influence on global environmental affairs but more often do not (Social Learning Group 2001a; Social Learning Group 2001b). Our most recent research has sought to explore this observation further to identify the factors that differentiate more from less influential assessments with particular focus being given to the institutional dimensions of assessment processes. 
Following recent work in international relations, we take "institutions" to be the formal and informal norms, rules, discourses, principles, and decision-making procedures that influence interactions between participants in an issue or problem area (Keohane 1998; Young 1992; Young 1999). Much of our work deals with transboundary, international, and global issues, and examines the role played in scientific assessments by international, national, and local level institutions. The influence of information depends on variation in the form of institutions, their degree of formalization, and the pathways by which they process information. Some influence the production of scientific knowledge directly through norms and procedures regarding setting research priorities, targeting resources, conducting experiments, assuring quality control, and disseminating results. Others guide the preparation and dissemination of scientific information to a range of audiences, from the international consortium of weather services to international environmental data collection collaborations to the recently-launched Millennium Ecosystem Assessment. Our comments are directed at a third group of institutions that focus on the direct use of knowledge in decision making. Such institutions create the norms and procedures of science advising, technology assessment, and formal scientific assessments. They produce public information for an audience that includes managers and decision makers engaged in behaviors and in promulgating policies directly involved in transboundary environmental issues.

\section{QUESTIONS AND ANSWERS}

How does scientific information influence the management of environmental issues? What distinguishes influential assessments from those which "sink without a trace?" How does an assessment's influence depend on the characteristics of the social institutions producing the assessment? How is informational influence conditioned by broader contextual factors? What 
strategies and conditions relevant to the use of information facilitate collective management of environmental issues, and which ones hinder such management?

We start with the simple observation that the influence of information varies. Over the last thirty years, hundreds of formal and informal efforts have been made to bring scientific information to bear on transboundary environmental problems. Some have significantly altered societies' responses to a problem, increasing the attention paid to it, altering the understanding of its causes, or prompting international policy development. Most, however, have had little, if any, influence (Social Learning Group 2001a). Our research has sought to explain this variation and, in so doing, to understand how institutions influence the impact that information has on the development of global environmental issues. Below we summarize here several major findings from our work. These findings are developed further in subsequent sections of this paper:

1) Scientific assessments can influence policy on transboundary environmental issues, but influential assessments are the exception rather than the rule. Even influential assessments rarely impact policy choice directly, but rather exert substantial indirect influence on long term issue development: When assessments are influential, they seldom have direct impacts on decisions to negotiate or sign treaties or to adopt specific policies. Rather, assessments usually exert indirect influence on the long term development of an issue area or domain via impacts on:

* who participates actively in discussions about the issue;

* how discussions and negotiations about the issues are framed;

* what policy goals, management options, and technical knowledge are emphasized (and which de-emphasized) in those discussions; and 
* the visibility of a particular issue relative to others competing for the scarce attention of scientific, policy, and public elites.

\section{2) The most influential assessments are those that are simultaneously perceived by a} broad array of actors to possess three attributes: saliency, credibility and legitimacy. Precisely because assessments have the potential to influence issue development, policy-relevant actors are attentive to the processes that create an assessment as well as the product of those processes. In particular, an assessment's influence on a particular policy-relevant actor is strongly conditioned by three attributions that the actor may make about the assessment's content and the process that created it. We refer to these three judgments as attributions because they are not objective, or even readily agreed-upon, characteristics of an assessment but rather involve actor-specific judgments using different criteria and standards:

* Saliency reflects whether an actor perceives the assessment to be addressing questions relevant to their policy or behavioral choices;

* Credibility reflects whether an actor perceives the assessment's arguments to meet standards of scientific plausibility and technical adequacy; and

* Legitimacy reflects whether an actor perceives the assessment as unbiased and meeting standards of political fairness.

Although perceived deficiencies in one attribution may be partially offset by strengths in another, policy-relevant actors tend not to be influenced by assessments that they perceive to fall below a minimum threshold level on any one of these attributions. Moreover, assessments, if they are to be influential, need to satisfy these constraints for multiple actors simultaneously.

3) Efforts to enhance the perceived saliency, credibility, or legitimacy of an assessment generally encounter difficult tradeoffs. Efforts to bolster one of these attributes usually 
succeed at the expense of another: Credibility, for example, can be maximized by limiting questions to those for which answers embody high levels of scientific certainty or by allowing only the most renowned scientists to participate, regardless of the nation or sector they represent. The problem is that in the former case, the assessment risks losing salience by failing to ask what decision makers want to know, and in the latter case risks losing legitimacy by not distributing participation across a range of interested actors. Likewise, simplistic efforts to raise legitimacy through democratically participatory assessments risk losing scientific credibility. And while decision makers can increase the chances of receiving advice salient to their particular interests by commissioning assessments "in house," the result is not likely to have much legitimacy in subsequent international negotiations. Assessments are more likely to be influential to the extent that they balance these tradeoffs so that minimum thresholds for all three attributions are satisfied, and satisfied simultaneously for multiple actors. As noted, this is no small feat. To make matters more difficult, the relative importance of saliency, credibility, and legitimacy in making an assessment influential change as an issue develops. Both thresholds and tradeoffs change as an issue progresses from early stages in which policy-relevant actors attempt to push new issues onto the international agenda, toward later stages in which those actors attempt to get national policy agendas to engage issues already being addressed at the international level, toward still later stages in which those actors attempt to induce local decision makers to take action in response to international agreements.

4) Institutions shape the influence of assessments in large part by shaping the tradeoffs among saliency, credibility and legitimacy, and providing the context within which those tradeoffs can be balanced by assessment designers. Three institutional features turn out to be particularly important in determining an assessment's potential influence: 
The embeddedness of an assessment reflects the degree to which it is carried out within, or under the control of, the organization that will subsequently use the assessment to inform or justify its policy decisions. (In the sense we use it here, an assessment on the hazards posed by fine particulate air pollutants would be strongly embedded if carried out by the Environment Ministry responsible for regulating fine particulates or corporation trying to set its own strategy, but relatively weakly embedded if carried out by an independent academy of science or university). Assessments that are too strongly embedded risk being dismissed as self-serving propaganda for decision makers (low legitimacy); those too weakly embedded risk being ignored as irrelevant by those decision makers (low saliency).

Boundary spanning arrangements bridge the gap separating experts involved in carrying out a scientific assessment from the decision makers who might use the assessment. Institutional arrangements must help decision makers effectively convey the policy questions they want answered to scientists and help scientists effectively communicate their findings to decision makers. These decision makers are not just policy makers in Washington, DC or Harare, Zimbabwe but also include farmers in the American Midwest and in Zimbabwe, coastal zone managers in Maine and Hawai'i, and power plant operators in Bulgaria and Poland (see Cash, , Patt, Moser, and Botcheva-Andonova chapters in Mitchell et al., forthcoming). If boundary spanning is too weak, scientists and decision makers will not hear each others' concerns or insights accurately, leading to low influence through a loss of saliency. If boundary spanning is too strong in coupling producers and users of assessments, suspicions arise that policy makers are not only asking the questions but also determining the answers, thus reducing the credibility of the assessment - and thus its influence. At the global level, environmental assessments must connect science and decision making across multiple spatial scales from the global to local. 
Effective institutional arrangements for boundary spanning facilitate agreement between scientists and decision makers over what questions an assessment will address, what kinds of evidence and expertise it will employ, and what processes it will follow.

Provisions for learning and critical self-reflection are important in balancing the benefits of continuity and cumulative experience in the assessment process with the need to track the changing needs of decision makers and the changing state of scientific knowledge. The need for periodic reviews of assessment designs is all the more important given the previously mentioned changing tradeoffs among saliency, credibility and legitimacy that are encountered in the course of issue development. On the one hand, there are many examples of assessments that are so rigid and unreflective that they become mired within the structures and procedures they developed early in their history, even when the development of the issue they have been addressing makes it clear that significantly different approaches would now be required to achieve a more influential mix of salience, credibility and legitimacy. On the other hand, trying to solve these problems of too much rigidity in assessment institutions by going to the extreme of ad-hoc (onetime) assessments can reduce the opportunities to build the issue networks, secretariat skills, and cumulative trust that appear so central to many influential assessments.

This remainder of this paper proceeds with a framework for understanding the influence of information on issue evolution. It highlights how scientific assessments have influenced the development of global environmental issues, focusing particularly on participation, issue framing, and substantive knowledge. We discuss the types of assessments that influence issue development and those that do not, focusing on attributions of saliency, credibility, and legitimacy. We then address the ways in which institutional design mediates the tradeoffs among saliency, credibility, and legitimacy in global environmental assessments. We conclude 
by linking our collective effort to other areas of theoretical and empirical work on the changing role of information in world affairs.

\section{A FRAMEWORK FOR UNDERSTANDING}

Our research was initially motivated by a desire to determine whether scientific information contributes to improvements in global environmental management (Social Learning Group 2001a; Social Learning Group 2001b). Ultimately, the environmental value of scientific information lies in its ability to induce changes in policies and behaviors that reduce human impacts on the environment. The influence of changes in economic, legal, and political structures are often readily visible because they alter the incentives and opportunities that are the proximate determinants of behaviors and policies. Information and ideas also may have such direct impacts but, more often, shape behavior in deeper, and less obvious, ways. In most arenas, ideas influence policy, political action, and "issue cycles" only over long timescales (Downes 1960; Kingdon 1984; March 1988; Sabatier 1993; Weiss 1975). Global environmental issues such as marine oil pollution, stratospheric ozone depletion, and acid rain have taken decades to develop from scientific curiosities to issues of high international politics and effective policy implementation (Mitchell 1994; Social Learning Group 2001a). Informational influence often not only takes time but operates through mediating or intervening factors that can make identifying its influence difficult. This "indirectness" has three analytic implications. It requires care in avoiding inferring that any changes in policy or behavior that occur after an assessment were caused by that assessment. At the same time, it requires avoiding concluding from the absence of immediate changes in policy or behavior that the information had no influence. Most importantly, it requires identifying the intervening factors that, when influenced by information, 
drive issue development and eventually the policies and behaviors associated with it in new directions.

\section{What's to be explained? Changes in the issue domain}

Because information often will not induce direct, proximate, and obviously-related changes in policies and behaviors, we have searched for evidence of informational influence in the intervening variables through which information can influence policy and behavior. In casting this broader gaze to identify informational influence, we built on Sabatier and JenkinsSmith's notion that "the most useful unit of analysis for understanding policy change ... is not any specific governmental organization or program, but a policy subsystem" or what we call an "issue domain" composed of "group of people and/or organizations interacting regularly over periods of a decade or more ... within a given policy area" (Sabatier and Jenkins-Smith, 1999, 119,135 ). Often even before these groups try to promote particular policy actions (as argued by Sabatier and Jenkins-Smith), they try to create shared understandings of the problem, the need for action, and the range of possible solutions.

An issue domain is characterized by interactions among different coalitions of actors who share concern for the issue at hand but often have different perspectives and policy preferences (Sabatier and Jenkins-Smith, 1999). Scientific assessments often consist of efforts to construct shared understandings among such groups. Some assessments are carried out in an advocacy mode. Others strive to adopt a policy- or outcome-neutral stance, and to avoid any appearance of advocacy. Within an issue domain, the beliefs of actor coalitions, their resources, the institutions that govern their interactions, and their collective decisions not only define the issue domain at any given time but influence its future development (Sabatier and Jenkins-Smith, 1999). Understanding scientific assessments in this light points to the importance of attending to who 
participates in assessments, what beliefs the assessment addresses, and how the assessment process itself is framed. Although we cannot assume that changes in these intervening variables will lead to changes in policies and behavior, it strikes us as reasonable to assume that without such changes, policies and behaviors will not change. Thus, we consider changes in these intervening variables as necessary but not sufficient conditions for policy and behavior change to occur in response to information.

Besides the influence of particular elements of the issue domain, contextual factors such as other policy issues, distribution of power among interested groups, general socio-economic conditions, public opinion, and external crises and shocks play a role in issue development. These contextual considerations are particularly important in that scientific assessments often raise the profile of an issue among those who had paid it little attention and thereby induce them to engage in the issue domain. Understanding such "recruitment" requires recognizing that other issue areas make demands on the scarce time and attention of potential recruits. Equally important, the challenges faced by an assessment differ considerably depending on whether it is conducted as an issue is emerging or later, during periods of policy formulation or policy implementation.

\section{Information as a source of (in)stability in the issue domain}

If scientific assessments sometimes influence issue development, what is the mechanism of such influence? The question of how assessments influence policy is of interest in no small part because of the strong assumption that policy, particularly international policy, is driven by the material interests and power of national governments (Keohane and Nye 1989; Waltz 1979). The prospect that assessments can improve global environmental management without any change in the "real" underlying forces that we assume drive behavior is tantalizing. We have no 
illusions that "science" can replace "politics." Yet, we want to understand how science shapes, channels, and influences politics. How can altering information, rather than material incentives or opportunities, alter the development of an issue?

To answer this question, consider the rationality assumptions that undergird most theories of state and individual action (see, for example, Green and Shapiro 1994; Checkel 1997; Koremenos, Lipson and Snidal 2001; Martin 1993; Shepsle and Bonchek 1997; Walt 1999). These assumptions imply a world in which behaviors reflect a relatively stable equilibrium among actors' goals, the expected outcomes of the options available to them given their resources, and their knowledge about the world. Indeed, the prevalence of the rationality assumption is evident in how we explain behaviors that do not appear to align with an actor's goals. In extreme cases, we may refer to a state or individual as irrational. More frequently, however, we make sense of the behavior by searching for unexpected goals, behavioral constraints, or knowledge imperfections that make the state's behavior appear "rational" by bringing the dissonant element of the goals-options-knowledge triad into consonance with the other two elements. Even literatures that question the assumption that states and individuals are always rational nonetheless involve assumptions of a stable goals-options-knowledge equilibrium. Thus, in the economics of information literature, if the "search costs" of collecting and processing information for a decision are high, behaviors that appear less than rational are reinterpreted as attempts to maximize benefits after accounting for search costs. The bounded rationality literature argues that, because cognitive capacities are limited, humans use rules of thumb and other heuristics to make decisions (March 1978). Similar assumptions underlie much of the international relations work on the emergence of cooperative and collective behavior 
(Axelrod 1984; Axelrod and Keohane 1986; Axelrod 1997; Schelling 1978; Schelling and Halperin 1960/85).

Considerable evidence shows that typically long periods of relative stability in society's attention to and management of particular issue domains are punctuated by shorter episodes of rapid change (Kingdon 1984; Baumgartner and Jones 1993). For transboundary environmental issues, these patterns of punctuated equilibria in social response are exhibited at both the international and domestic level (Social Learning Group 2001a; Social Learning Group 2001b). We see scientific assessments as either helping stabilize the "normal" equilibria among goals, options, and knowledge or helping precipitate the occasional destabilizations of those equilibria. The characterization of the issue domain sketched above leads us to look for ways in which new information alters which "actor coalitions" actively participate in a particular issue domain, what beliefs they hold about the world, what resources they have, and what institutions govern their interactions. In the next section, we review insights from our research agenda regarding which of these potential mechanisms actually matter in connecting scientific assessments with the evolution of global environmental issues.

\section{HOW INFORMATION HAS INFLUENCE}

Our research suggests that information influences the evolution of transnational environmental issue domains through three principal pathways: by affecting who participates in assessments, what is discussed in assessments, and how things are discussed in assessments.

\section{Who discusses: participation}

Assessments often wield influence by drawing the scientists who author them into an issue domain. Because assessments tend to focus on scientific aspects of a problem, while 
highlighting corresponding uncertainties, they often prompt policy makers, segments of the public, the media, and advocacy networks already involved in the issue domain to seek out scientists for policy advice (Haas, 1990). Assessments raise the visibility of scientists involved in an assessment but, if uncertainty is high, also raise the attention paid to those with opposing views (Litfin 1994). To the extent assessments resolve uncertainties (or as uncertainties are resolved for exogenous reasons), however, they tend to marginalize scientists propounding facts, causal beliefs, and forecasts that the assessment characterizes as outside the "mainstream" (Franz, 1998).

Assessments also influence the policy debate by drawing new actors into it, altering the pre-existing balance among participants (Farrell et al. 2001). Many actors, of course, are unaffected by exposure to the new information. But others who are made aware of a problem by an assessment will enter the debate and seek to broaden, narrow, or shift it if they believe policy responses will serve or harm their interests (Schattschneider 1975). They will publicize those elements of an assessment they believe will mobilize bystanders with coincident interests to enter the issue domain while trying to avoid highlighting elements that would mobilize their opponents (Litfin 1994). Even if the "attentive public" expands only briefly, some subset of actors is likely to remain engaged and mobilized, with the boundaries of the conflict unlikely to return to their previous contours. Assessment efforts often attempt to engage participants from multiple levels or demonstrate implications of global assessments to national and subnational actors. Framing global environmental concerns in ways that connect local concerns to global phenomena can broaden the array of actors in the issue domain. It also can pose challenges for scientists in collaborating across scale and linking levels of analysis. Such challenges were evident in the US National Assessment of Climate Change's efforts to integrate regional and 
national assessment components, in Great Plains water management (Cash, in Mitchell et al., forthcoming), and in linking global ENSO forecasting with subnational decision making in southern Africa (Patt, in Mitchell et al., forthcoming).

Even when they do not engage new actors, assessments increase the attention and concern of those already engaged in the debate. Simply by putting an issue on the policy agenda or raising its visibility on that agenda, an assessment leads many actors - and may require policy makers - to discuss the issue. And assessments rarely produce information that is impartial in its effects on the policy debate. Some sectors are activated while others remain quiescent, thereby realigning the balance of power among groups active in the issue domain. Assessments usually increase the difficulty of making certain arguments and of refuting others. They often shift the burden of proof from one side of a debate to the other. They lead advocacy networks to change both the magnitude of resources and the types of strategies they deploy in their attempt to influence subsequent issue development.

\section{What is discussed: goals, options, and knowledge}

Changing the participants in an issue domain and their rhetorical power effectively alters the goals pursued in the issue domain. We can consider the "goals of an issue domain" as the outcome of the process by which that domain aggregates the goals of mobilized actors. Goals may shift in response to an assessment because the assessment leads new actors to join the debate and leads existing actors to mobilize (or demobilize) resources. Nor are actors' goals completely exogenous or immutable. Actors generally have multiple goals, only some of which are activated in a given issue domain at a given time. Increasing the attention paid to an issue can increase the priority of certain goals, while decreasing the priority of others. Environmental assessments, for example, often induce a shift from decisions pursuing strictly economic goals to 
decisions making trade-offs between economic and environmental goals. Environmental impact assessments add new considerations to a power plant citing decision, for example, while also calling into question the overarching set of goals being pursued by policy makers. Even if actors' goals are relatively stable in the short term, assessment processes can initiate dialogues among actors that can alter underlying goals over time. Continuous and consistent foregrounding of certain goals and backgrounding of others can, over time, lead advocates to give the former more consideration over a wide range of issues and decisions, while the latter become increasingly discounted or disregarded. Such effects of assessments on goal reorientation may be large, even if difficult to verify empirically.

Assessments also can alter the options considered as available and how seriously those options are considered. Sometimes assessments can introduce truly new options into an issue domain. The Convention on Long-Range Transboundary Air Pollution (LRTAP) adopted regulations based on transboundary fluxes and critical loads of acid precipitants only after a research team at the International Institute for Applied Systems Analysis' (IIASA) had developed the techniques needed to identify those parameters of the problem. Usually, however, more material resources are needed to change the available behavioral options with assessments changing the perceived costs and benefits of available options. At the simplest level, assessments increase the political costs of doing nothing by increasing the attention paid to an environmental issue. They shape debate by considering some options and ignoring others. Thus, the debate over stratospheric ozone depletion was channeled, in part, by the fact that most assessments of alternatives to CFCs focused on chemical substitutes rather than more fundamental replacements for CFC-using technologies (Parson, 2002). Options not evaluated often vanish from subsequent debate as arguments focus on the options that were considered. 
Policy makers rarely simply adopt the prescriptions set forth in an assessment, but those prescriptions do shape debate, shifting the burden of proof to those who disagree with the assessment's claims about preferred and passed-over options. Participants that believe they have much to gain (or lose) from adoption of a given alternative will mobilize in response to an assessment. Thus, assessments often shape the debate even if they do not dictate its outcome.

Not surprisingly, assessments wield much of their influence by altering the perception of facts, causal beliefs, and scenarios regarding potential futures. These components of knowledge are central to the judgments participants make about which behavioral options available to them will most further their interests. New causal beliefs in an assessment alter actors' predictions about the results (and hence the benefits and costs) of engaging in certain behaviors. Assessments often provide estimates of the current state, and projections of the future state, of the world that are necessary to, and therefore influence, choices among alternatives. But, assessments always consider a limited set of options and report a limited set of characteristics of future worlds. Those limits usually combine the artifacts of limitations on knowledge as well as conscious and unconscious judgments regarding what aspects of potential futures should be considered in the policy debate. Most climate change assessments, for instance, have not forecast either country-level impact scenarios or the effect of different global scenarios on income distribution or life expectancies. Even when such truncation of evaluative criteria reflects scientific necessity rather than normative biases, it influences subsequent issue evolution. Reporting certain criteria reinforces the importance of those criteria while implying that others are appropriately minimized or ignored. To take a common example, the analytic difficulty of incorporating non-monetizable values in economic analyses often has the effect, however unintended, of leading participants to ignore non-monetizable values and to consider doing so as 
politically appropriate. Assessments also influence perceptions of uncertainty. Although they often increase the level of scientific knowledge in the debate, both "facts" and uncertainties are treated much differently by policy makers than they are by those producing the assessment. Uncertainty in general and nonlinearities in particular frequently get "lost in translation," in no small part because of the media's efforts to simplify (Patt, 1999). At the same time, both opponents and supporters of an assessment's policy implications often highlight uncertainties in an effort to either discredit the conclusions and thereby prevent policy change or to mobilize potential participants by highlighting "worst case scenarios" (Patt, 1999).

\section{How things are discussed: discourse and framing}

Assessments also wield influence by framing policy debates. Framing involves the oftenimplicit rhetorical processes that link goals, options, and cause-effect knowledge. Assessments can influence the framing of an environmental issue by highlighting certain linkages while obscuring or ignoring others. As most assessments enter the political arena, their nominally scientific claims identifying certain behaviors (and not others) as major causes of an environmental problem become politically-charged allocations of blame for the problem and responsibility for its resolution. Certainly assessments intended to address the "science" of climate change have been used by various sides in the debate in these ways.

Issues are framed as much by what information is included and excluded as by how included information is worded, used, shaped, and contextualized. Framing is both an unselfconscious artifact of the interests, biases, and blindspots of those conducting the assessment and a very self-conscious effort by those interested in influencing the behavior of others. Framing plays a crucial role in whether an assessment disrupts the existing equilibrium of goals, options, and knowledge by convincing (or failing to convince) participants that current policies and 
behaviors no longer represent the best ways to achieve their goals. Framing that influences one advocacy network may fail to influence another. Global assessments often wield more influence in developed countries because their framings are more consonant with existing policy concerns and objectives in those countries than in developing countries. Thus, initial framing of stratospheric ozone loss as a global commons problem in which all states shared responsibility fit with public perceptions in developed countries, leading them to support international action. By contrast, governments and publics in many developing countries viewed this framing as selfserving, opposing international action until the problem was reframed as one in which developed countries took responsibility for both the problem and its resolution. The framings of an assessment influence both choices among near-term policy options and choices among scientific research programs, thereby influencing, over the longer term, how quickly, how well, and in what ways we understand future environmental problems.

\section{WHEN AND WHICH INFORMATION HAS INFLUENCE}

Information can influence an issue domain by altering who participates, what is discussed, and how issues are discussed. But, it is precisely the fact that information does not always influence an issue's development that motivated our research. Self-conscious and unintended changes, as well as exogenous (e.g., an economic downturn or political turmoil) and endogenous ones (e.g., social learning or dramatic environmental changes), can alter the state and the dynamics of a domain. Efforts by actors to use material resources to change an issue domain by altering the incentives or opportunities facing other actors have received considerable scholarly attention (see, for example, Mitchell 1994; Brown Weiss and Jacobson 1998; Chayes and Chayes 1995; Victor, Raustiala and Skolnikoff 1998). We focus, however, on scientific information as a potential driver of issue development. Our research has led us to conclude that 
information is more likely to have influence with a particular actor to the extent that the actor believes the information to be salient, credible, and legitimate. This section develops these three concepts and is followed by a discussion of the processes by which assessments gain, or lose, saliency, credibility, and legitimacy.

\section{Saliency}

To influence issue development, an assessment must be salient, i.e., it must be both noticed and deemed relevant, to participants in the issue domain. Assessments may lack salience, and therefore lack influence, for various reasons. Questions raised in an assessment may be important to the scientific community but not to the potential users of the information. Assessments often adopt a "one size fits all" approach instead of tailoring the analysis to specific users and specific contexts. Assessments may answer salient questions too slowly to play a meaningful role in rapidly evolving policy processes. Assessments may arrive before advocates in the issue domain have any interest in the information or after decisions have been made and policy interest has subsided. In addition, assessments may provide solutions that are at a different scale or have a different scope than needed by users (See Cash, Patt, Moser and Torrance chapters in Mitchell et al., forthcoming).

Even assessments that are salient to a large set of actors fail to be salient with certain actors and will have elements that fail to garner much attention with any actors. Findings considered central by the assessments' creators can be ignored by certain actors, while assumptions given little thought can become a major focus of debate. Thus, negotiation of the Cartagena Protocol on Biosafety included considerable debate over whether to include socioeconomic considerations in information sharing provisions regarding genetically modified organisms (such as how such provisions would alter trade relationships and dependencies). 
Including the socioeconomic dimensions of biosafety within the scope of the information sharing system was crucial to the system being perceived as salient and legitimate by developing countries and environmental groups (Gupta, in Mitchell et al., forthcoming). Policy options considered in an assessment that do not recognize political constraints may be ignored altogether while others, considered inferior in the assessment, become the focus of debate. The very media through which an assessment becomes salient regularly reduces long assessment reports to soundbites of a few facts and causal linkages. Much American media simplified the conclusion of the IPCC's 1995 report to noting that there was "a discernible human influence" on climate, often (though not always) providing the public with little sense of the full document's discussion of the range, uncertainty, and assumptions underlying that and similar claims. Assessments also can become salient when a participant in an issue domain responds to an assessment not because they view it as directly relevant to their own decision-making but because they believe that other actors will do so in ways that make it worth paying attention to the assessment. Thus, Central and East European governments became more attentive to LRTAP-related assessments of acid rain only when they came to see those assessments as policy guideposts that could help facilitate their entrance into the European Union (VanDeveer, in Mitchell et al., forthcoming).

\section{Credibility}

For an assessment that captures some actor's attention to influence their behavior, that actor must consider the assessment credible. That is, the actor must consider the facts, theories, causal beliefs, and options in the assessment as worth believing. This attribution of credibility by that actor involves a view that the information is either "true" or, at least, worth using instead of competing information. 
Participants often cannot assess independently whether to believe the information in an assessment. Indeed, the epistemic community literature starts from the premise that it is precisely in arenas of uncertainty in which policy makers cannot make judgments for themselves that they turn to scientific experts (Haas 1992). In such cases, policymakers and participants in an issue domain must evaluate an assessment's credibility indirectly. Participants often assess "credibility by proxy" based on the process of assessment. Assessments tend to be discounted by those who believe the process allowed "interests" rather than "science" to determine their contents.

The credentials of the generators of an assessment also influence its credibility. Although what constitutes "credible" credentials varies from audience to audience, participants generally view sources as credible if they have produced information that the recipient has found valid in the past. Credibility also can be based on a recipient's perception of whether an assessment's producers have expertise, i.e., know whether the information being reported is true or not, and are trustworthy, i.e., will report that knowledge honestly. Expertise is often promoted by including top scientists. Trustworthiness is not based on the belief that those producing the assessment lack biases and policy interests, but on the belief that those interests do not drive the knowledge creation or dissemination process. Thus, even those willing to recognize the expertise of the producer of an assessment may not trust them, as evident when assessments are critiqued on the basis of funding rather than credentials.

Finally, credibility depends on the degree of consensus in an issue domain. Credibility is hard to establish in arenas in which considerable uncertainty and scientific disagreement exists, either about facts or causal relationships. Indeed, actors opposed to an assessment's recommendations will highlight such uncertainty and disagreement in efforts to question an 
assessment's credibility. Information that is consistent with well-established information or enters an arena in which few alternative sources of information exist tends to have more credibility than that which refutes existing facts and theories or enters a hotly-contested issue domain. Notably, the scientific drive to reduce uncertainty tends to promote consensus, which tends, in turn, to reduce informational salience. As consensus increases, an assessment's credibility is resolved so that the assessment is widely accepted as credible or not, at which point actors in the issue domain tend to adopt other strategies to support or oppose the policy implications of the assessment.

\section{Legitimacy}

The legitimacy that policy participants and scientific participants in an issue domain attribute to an assessment depends on their belief that the process of the assessment conforms to their perceptions of procedural fairness and also considers their concerns. Policy participants judge the legitimacy of assessments, and whether they believe their concerns were properly accounted for, by evaluating the processes used to decide who participates (and who does not) and how information is produced, vetted, and disseminated. Even assessments that make recommendations that run counter to a participant's interests may be accepted as legitimate if that participant believes their concerns were considered, even if rejected. Participants often, though not always, recognize the need for tradeoffs among competing values and simply want to ensure their values were taken account of in making tradeoffs.

Actors raise issues of legitimacy when an assessment recommends behavioral changes that disproportionately harm their interests or benefit the interests of others. Questions of legitimacy regularly arise in assessments that cross the developed-developing country divide.

Whether intentionally or as an artifact of unrepresentative participation by developing countries, 
assessments often fail to include the concerns and perspectives of developing country citizens .

Even assessments that are salient and credible to actors in developing countries may not influence those actors if they believe their views and concerns were not considered. Moreover, assessments whose recommendations coincide with an actor's interests can also be questioned, if produced by those viewed by that actor as opposed to their interests. Like credibility, actors often assess legitimacy by proxy, judging the list of participants in the assessment or the process for generating inputs to and outputs from the assessment in terms of whether their values and concerns had any chance of being incorporated into, and addressed by, the assessment.

\section{THE INSTITUTIONAL CHALLENGE}

Perhaps it is not surprising that assessments are unlikely to exert influence to the extent that the information they produce is irrelevant, not believable, not trustworthy, fails to account for the interests and values of those it seeks to influence, or have processes that are deemed illegitimate. Yet many assessments fail to influence any actors and most fail to influence at least some important actors. Others, however, have had considerable influence and, based upon our research, we have sought to identify both the institutional challenges faced in producing an influential assessment and the institutional designs that successful assessments use to overcome those challenges. In this section, we summarize several findings about how institutional design influences attributions of saliency, credibility, and legitimacy as well as the tradeoffs and tensions that cut across these three attributions.

\section{Institutional challenges in promoting saliency, credibility, and legitimacy}

A consistent finding in this volume is that participation in an assessment plays a crucial role in its subsequent influence. Institutional choices regarding who can participate in an 
assessment, who cannot, and how different actors can participate have dramatic implications for how the assessment will be received by different audiences. For many actors in an issue domain, the easiest way to assess saliency, credibility, and legitimacy is to ask "Who wrote this assessment?" By being attentive to what different important audiences will mean when they ask that question, assessments can design participation rules that increase the assessment's influence with those audiences.

Many assessments construe the participation question as one of ensuring that all participants have appropriate "scientific credentials." Our research clearly demonstrates that this can enhance credibility within a scientific community, but that it may lack and even reduce credibility with other important audiences. Involving representatives of intended audiences in the assessment process fosters saliency by ensuring that the questions the assessment asks are the ones relevant to those audiences' policy and behavioral decisions. It not only ensures that the assessment answers salient questions but that it frames those answers in ways that resonate with intended audiences. Thus, early IPCC reports did not reflect Indian concerns regarding climate and framed the problem as caused by humans "all over the globe" rather than, as Indians did, as largely the result of developed state behavior (Biermann, in Mitchell et al., forthcoming). Credibility can be built by involving stakeholders in providing and analyzing data in ways that promote trust in the assessment's final conclusions. Involvement promotes transparency of the assessment process to intended audiences, clarifying that "science" rather than "interests" drove assessment conclusions.

Failing to include participants from important advocacy networks in an assessment process usually produces assessments that those participants see as irrelevant to their decisionmaking and as lacking legitimacy. Including representatives of different intended audiences 
promotes legitimacy by ensuring both that the assessment incorporates the views, goals, interests, and concerns of those audiences and that those audiences perceive it as having done so. Failing to incorporate such participation often leads to the concerns of these audiences being either misidentified or ignored altogether. For many audiences, participation in the process often becomes the defining indicator of whether they believe that their views were considered, and thus whether the resulting assessment is perceived as having a legitimate role in the policy process.

Our findings suggest that "representative participation" matters a great deal. Assessments are more likely to have influence to the extent that participants are representative of different countries and regions around the globe. Influence is also likely to be enhanced to the extent that the assessment process includes representation from local, national, and regional levels so that they can provide and frame information in ways relevant to the day-to-day decisions faced by decision makers at each of these levels - from government policymakers to farmers (see Patt and Cash chapters in Mitchell et al., forthcoming and Cash \& Moser, 2000).

Rules, both formal and informal, regarding how actors participate also can shape an assessment's influence. Since participants in assessments are usually volunteers, choices regarding the scope of an assessment determine who participates which in turn influences what sorts of arguments are considered legitimate. Both normative arguments and interest-based arguments are often considered inappropriate in an assessment context that is seeking to identify "the state of the science" on some environmental problem. Rules regarding how to incorporate dissenting scientific views influence how an assessment is received by audiences not yet convinced by the "consensus" view. Decisions not to identify the actors responsible for past, and likely future, contributions to an environmental problem or the actors likely to be most harmed 
by an environmental problem also influence how audiences view the usefulness and credibility of the assessment.

Assessments can use processes as well as participation to promote saliency, credibility, and legitimacy. They can design processes for input, feedback, and evaluation from relevant audiences actors, even without providing for direct participation. Where participants themselves are not representative, assessments can explicitly seek to identify questions likely to be relevant to important intended audiences. Assessments can identify questions of interest not only to actors already mobilized around the issue but those "latent" actors that can be, but are not yet, mobilized. Assessments of large-scale environmental issues can be more salient to regional and local actors by consciously addressing the multi-level nature of the problem and accounting for place-specific knowledge, concerns, and vulnerabilities.

Procedures governing the review of scientific findings and the editing of final reports can be designed to reduce the role of limited perspectives and particularized interests, thereby reassuring the scientific community and others of its credibility. Many global assessments involve hundreds of authors and adopt stringent and extensive peer review procedures to ensure that the assessment not only accurately reflects current understandings of the problem but also convinces potential audiences that it does so. Maintaining standards of scientific rigor provides process-based evidence of credibility that can counter questions that may arise from credentialbased evidence of credibility. Procedures to ensure and demonstrate impartiality can, over time, garner credibility for the assessment institution itself, leading its products to be viewed as credible almost without question, as evident in the influence of RAINS models in LRTAP and in global negotiations on persistent organic pollutants (POPs) (VanDeveer and Eckley chapters in Mitchell et al., forthcoming). 
Beyond participation and procedures, initial scoping plays an important role in an assessment's reception. Assessments produced in response to explicit requests from particular actors will be viewed as salient by those actors so long as the assessment addresses their issues and concerns. Assessments initiated by scientists are more likely to lack influence if they do not self-consciously attempt to identify questions currently relevant to decision-makers and to frame the answers to those questions in ways that can be adopted and implemented by those decisionmakers. Related to these initial issues, decisions regarding funding sources can wield significant influence over later perceptions of trustworthiness and hence credibility.

Assessments, once produced, may need to be "marketed" to actors who otherwise will be unaware that such assessments exist or contain information useful to their decisions. Scientists, NGOs, industry, and the media often help introduce elements from the assessment context into the issue domain. Breakdowns in this failure to structure and market assessments to respond to decision needs at the local level are obvious in the cases of management of the High Plains aquifer, coastal management in Hawai'i and Maine, and responses to El Niño forecasts in Zimbabwe. This requires not only that information in an assessment, and the framing of that information, fit with a recipient's perceived interests and perspectives but also be within that recipient's capacity to understand and incorporate it. The capacity to use information effectively varies considerably across intended audiences and effective assessments are attentive to the need to make their findings usable and to build capacity where it does not exist (see Cash, Moser, Patt, Biermann and VanDeveer chapters in Mitchell et al., forthcoming). Scientific capacity and infrastructure, either on the part of the recipient or provided through the assessment process, are needed to bridge the gap that often exists between a global assessment community and domestic and local policy making communities. 


\section{Tradeoffs among saliency, credibility and legitimacy}

Important tensions and trade-offs exist among saliency, credibility, and legitimacy. Trade-offs not only inhere in attributions of saliency, credibility, and legitimacy but also arise because those attributions are made differently by different actors. An assessment's influence depends on satisfying multiple audiences as well as multiple attributions by those audiences. A recurring, and frustrating, theme in the chapters that follow, is that saliency, credibility, and legitimacy usually do not come "in the same package." Achievement of one of these attributions usually neither ensures achievement of the other two nor is independent from them. Rather, the strategies, institutional mechanisms, and conditions that promote one attribution often undermine one or both of the other attributions.

The tradeoffs among the attributions of saliency, credibility and legitimacy mean that assessments often lack influence because they focus on one attribution to the detriment of the other two. Particularly often, assessments are designed by scientists who, not surprisingly, focus on making the assessment credible to the scientific community. But scientific findings derived through the scientific method that may convince other scientists often are far from influential in a world in which "disinterested" science wields little influence in a world of "identity" politics in which quite different notions of "truth" and "knowledge" hold sway (Tesh and Williams 1996). Indeed, although following the scientific method increases credibility with scientists, it may undermine credibility with other politically important actors.

Institutional design choices that enhance an assessment's credibility may undermine its legitimacy. Precisely because the scientifically most-qualified people in a discipline usually represent a non-representative societal sector from a non-representative sample of countries, global assessments that pursue credibility by engaging only such people will tend to ignore the 
perspectives and concerns of many actors who are central to the policy-making process in an issue domain. Nor will efforts to incorporate the views of non-participants in the assessment enhance legitimacy with these sectors if those sectors use participation as their basis for evaluating legitimacy. On the other hand, including non-scientists or poorly-qualified scientists in an assessment to enhance legitimacy or saliency with certain actors in the issue domain can undercut credibility. Some information institutions have managed this tension among attributions and audiences by involving non-scientific stakeholders in initial "scoping" of an assessment and in framing the final report, while having scientific experts manage the analytic components of the assessment.

Avoiding making policy recommendations or limiting an assessment's scope to areas of consensus may enhance credibility but make the assessment so distant from current policy concerns and debates that it fails to be salient to important political actors. Assessments of "what do we know" often do not resonate with those concerned about "what should we do." At the same time, attempts to make assessments salient by addressing important current policy problems may produce answers that lack credibility because they are operating at the edge of current knowledge. Limiting scope can also bring legitimacy into question. Restricting an economic assessment to monetizable elements upon which economics can credibly shed light may be deemed illegitimate by those who believe that non-monetizable elements are central to an appropriate understanding of the problem. The reluctance of economists to make recommendations regarding issues of equity or of scientists to make explicitly-value-based pronouncements may increase credibility but does so at the expense of legitimacy. At the same time, efforts by scientists to push a particular policy agenda can delegitimize an assessment, as evident when credible science from the Scientific Committee of the International Whaling 
Commission that certain harvest rates would not threaten the minke whale species was deemed illegitimate when it proceed to claim that, therefore, minke whales should be harvested (Mitchell 1998).

Influential assessments tend to identify strategies that minimize these tradeoffs and tensions. Successful designers seek out assessment participants who are simultaneously credible with the scientific community but representative of the different audiences in the issue domain. They design assessments to include participation from important audiences at points in the process where they can promote the assessment's legitimacy without impinging on its credibility. They cautiously frame assessment results to remain "true to the science" (and hence credible) but address major elements of the policy debate and so are salient. The relative importance of salience, credibility, and legitimacy varies depending on the stage of issue development, with what appear to be trade-offs involving instead the strategic elevation or lowering of one or the other of these attributions as appropriate to a particular stage of issue development. Perhaps the most important design feature of successful assessments is simply being attentive to the tradeoffs and tensions mentioned here, and struggling to design the assessment to attend to all three attributions with as many audiences as possible.

The GEA research effort has shown that institutions shape the influence of assessments in large part by shaping the tradeoffs among saliency, credibility and legitimacy, and providing the context within which those tradeoffs can be balanced by assessment designers. Three institutional features that have turned out to be particularly important in determining the influence of scientific assessments of transnational environmental issues are described below. 


\section{Institutional embeddedness}

Institutional embeddedness, as defined in this volume, is the degree to which scientific assessment processes are circumscribed by the organization using the assessment to inform or validate its policy decisions. In a recent edited volume that targets science-policy interactions much in the same way this volume does (Andresen et al., 2000), the authors explore the relationship between different dimensions of science-policy interactions and the uptake of scientific knowledge and advice by policy actors. These dimensions are organized under the categories of "autonomy" and "involvement" and include such characteristics as merit-based recruitment of participants, operational autonomy and independent coordination of research, functional differentiation between research and advice, and the formalization of links between scientific research and decisionmaking bodies. Our understanding of embeddedness incorporates many of the elements that would correspond to lower autonomy or greater involvement in Steiner et al.

Our impression of the relationship between embeddedness and influence seems generally consistent with Steiner et al.'s finding that higher levels of autonomy and less involvement may impede the transmission of scientific knowledge to policy actors in spite of their perceived salutary effects on the credible production of knowledge. Two possible causal mechanisms might be considered. First, as implied by Steiner et al., one might posit that higher levels of embeddedness will positively effect the saliency of information provided to decisionmakers though risking some of the safeguards on scientific credibility. Second, it is quite possible that all three attributions (saliency, credibility and legitimacy) will be positively affected by higher levels of embeddedness for actors within the embedding institution or organization (its decisionmakers) but negatively affected for actors outside of it (other affected stakeholders). 
The net impact for an assessment's influence on a given issue will then depend upon the level of contestation in the issue domain (or the political malignancy of the issue, as understood in Steiner et al.) and the degree to which the embedding institution or organization represents the range of interests affected by the assessment. Embeddedness will likely enhance the influence of assessments conducted within broadly representative institutions or organizations and on less contentious issues while weakening the influence of assessments conducted within institutions perceived as partisan and on highly contentious issues.

Thus, the considerable influence of IIASA's Regional Air Pollution Information and Simulation (RAINS) project (an assessment institution) on efforts to control acid precipitation in Europe owed much to the highly embedded relationship between the RAINS project and the institutions of the Convention on Long-Range Transboundary Air Pollution; indeed, RAINS reports and models were awaited as crucial inputs to the LRTAP policy process (VanDeveer, in Mitchell et al., forthcoming). At the same time, the RAINS assessment had much less influence within the East European states of Poland and Bulgaria where tight institutional linkages to relevant decisionmaking bodies were absent (Botcheva-Andonova, in Mitchell et al., forthcoming).

Yet, more embeddedness is not always helpful. As shown in the Newfoundland fisheries case presented in this volume, the increasing politicization of northern cod assessments and the growing rift between inshore and offshore fishers altered the implications of embeddedness. The highly embedded characteristics of the science functions of the Canadian Department of Fisheries and Oceans switched from serving as an asset for the swift uptake of scientific advice in the late 1970s and early 1980s to a liability in the late 1980s and early 1990s (Alcock, in Mitchell et al., forthcoming). 


\section{Institutions for spanning science-policy boundaries}

Besides questions of embeddedness, assessment institutions must bridge the gulf separating those carrying out an assessment from those using the assessment. Assessment institutions are designed to serve the goals of sovereign governments. But their effectiveness in doing so depends on their ability to reflect the knowledge, concerns, and values of sub-national actors. Mobilizing sub-national actors in support of international policy is crucial to cooperation in the fields of trade, communications, and human rights but is particularly acute and visible in environmental affairs. Recent research in science and technology studies highlights how the science-policy boundary is socially constructed, porous and evolving, and negotiated and contested continually by both scientists and policy makers (Jasanoff 1987; Gieryn 1995; Guston 1999). "Boundary organizations" facilitate communication and mediate such boundaries (Guston 1996; Guston 1999). In issue areas characterized by high demand for technical information - and in most arenas due to the advance of the information age - the effective use of science in policy and decision making increasingly requires institutions that can cross "the functional and cultural boundaries between domains of jurisdiction and scales of organization" and "straddle the shifting divide between politics and science" (Guston, Clark et al. 2000, 1).

Boundary organizations mediate the ongoing demarcation of the line between science and policy, clarifying what can and cannot cross the boundary, and what qualifies as legitimate and credible action and information originating on either side. Discussions about participation, peer review, and what data to include and exclude all serve to demarcate the boundary in ways that influence the saliency, credibility, and legitimacy of an assessment. This complex mediation and negotiation across a boundary requires that members of an institution have legitimate standing on both sides of the boundary. A boundary organization can also legitimize the use of "boundary 
objects" such as reports, forecasts, and models that are "both plastic enough to adapt to local needs and constraints of the several parties employing them, yet robust enough to maintain common identity across" boundaries (Star and Griesemer 1989, 393; Botcheva-Andonova, Patt and Cash in Mitchell et al., forthcoming).

While theories of boundary organizations have generally been used to analyze interactions between science and policy, they also shed light on interactions across spatial scales (Cash 2001). Global assessments often lack influence at the local level because they fail to frame global knowledge in ways that local decision makers view as salient. Local decision makers (whether farmers, city planners, or coastal zone managers) are usually unaware of global assessments or find their recommendations irrelevant to their decision-making. Global assessments that try to make local level claims often find those claims lack credibility or legitimacy with local audiences who, often correctly, view their local knowledge and local concerns as having been ignored. Indeed, often the necessity of aggregating global-scale information causes global assessments to lose the locally specific and salient information and policy recommendations that are usually most needed by local decision makers.

The multi-level nature of many global environmental problems highlights the difficulties of managing participation, goals, options, knowledge, and framing. Attributions of salience, credibility, and legitimacy exhibit strong scale-dependence. A treaty relevant to national actors ("aggregating over our country, this is how a resource can best be allocated"), might not be salient to local actors (“our concerns are not reflected in the nation's overall plan"). Regulations set through international agreement, while legitimate to national actors ("after all, our country was involved in negotiating the agreement"), would not be legitimate actions in the eyes of subnational actors ("we've had no input into the rules that affect our livelihoods.") The IPCC 
assessment, while credible to scientists engaged in global scale modeling ("the IPCC has the best climatologists as authors, plus it's been peer reviewed"), might not be credible in the eyes of subnational scientists ("their models do not capture the specific conditions here.") Institutional mechanisms which acknowledge and address the various levels of a problem often avoid disjunctures due to scale. Boundary organizations can provide linkages across levels while providing sites for negotiating the boundaries between levels (e.g., defining what the scale of a problem is); integrating and communicating goals and knowledge across different levels, to better address the place-specific issues and concerns of sub-national actors, and testing multiple options; framing the problem (climate change as an emissions problem vs. climate change as a public health problem) to more accurately correspond with sub-national concerns and thus heighten the profile of the issue; and capitalizing on scale-dependent comparative advantages for information production and use (Cash, this volume).

Global assessments are often most effective when they are responsive to local level attributions of salience, credibility, and legitimacy while also creating and disseminating shared knowledge that has adequate salience, credibility, and legitimacy at national and international levels of policy making. Scale-differentiated assessment processes provide particularly effective institutional solutions to the challenge of linking knowledge and action across various spatial and governance levels. The effectiveness of the assessments analyzed in several chapters in this volume (or the lack thereof) demonstrate both the difficulty and the necessity of being attentive to local level participation in and responsiveness to assessment processes if those processes are to be viewed as salient, credible, and legitimate at the multiple spatial and governance levels needed to alter environmental behaviors. 


\section{Institutions for learning and critical self-reflection}

Scientific assessments play an important, if seldom dominant, role in the processes of social learning by which the world has increased its ability to deal with trans-boundary environmental risks (Social Learning Group, 2001). Perhaps not surprisingly, research conducted under the GEA project has suggested that assessment processes are more likely to fulfill their full potential as facilitators of social learning to the extent that they themselves have institutionalized provisions for critical self-reflection and external evaluation. Making such provisions involves balancing a set of institutional tradeoffs focused on the long-term continuity of assessment processes.

As noted earlier, we found that scientific assessments are usefully interpreted as social processes involving communication between experts and decision makers. At one extreme, the process can be quite short, involving ad-hoc assessment teams assembled for a specific purpose that produce a report and then disband. At the other extreme, assessments such as those on fish stocks conducted by the International Commission for the Conservation of Atlantic Tuna or the International Council for the Exploration of the Seas have become permanent institutions with standard operating procedures, specialized staffs, and a cumulative record of products. In between are assessment institutions such as the US National Research Council that, in general, produce ad-hoc assessments but do so using a stable set of procedures and against a background reputation gained in other assessment studies.

Distinct opportunities for, and challenges to, learning arise across this range of continuity in the assessment process. The more permanent assessment institutions would seem to have a potential advantage deriving from their abilities to reflect upon their previous experience in the same assessment problem, to build networks of experts and decision makers experienced in 
working with one another, and to capture lessons learned in their secretariat staffs, assessment participants and operating procedures. At the same time, however, these institutions incur the potential threats to learning associated with any large scale organization: reluctance to risk the institution's reputation or future by admitting error, careerism among staff, conservatism in structures and procedures, and development of a relatively closed circle of senior players. In short, they tend to get better and better at "doing the job right" but are less and less likely to be "doing the right job." In contrast, more transient assessments have the potential advantage of fitting their players and processes to the needs of the moment, free of restrictions anchored in the past. The risk, of course, is that unless they are creative in their use of others' previous assessment experience, they are bound to end up re-inventing networks of participants, recommitting even the most obvious of their predecessors blunders, and leaving little behind for the future to build on. Other things being equal, assessments conducted under such institutional circumstances have a relatively good chance of "doing the right job", but a proportionately lower likelihood of "doing the job right."

In our studies, we found little evidence that ad-hoc, one-time scientific assessments exert much influence on transnational environmental affairs. In contrast, many of the most clearly influential assessment processes we studied were long-lived iterative affairs, with reports issued at periodic intervals. Examples include the IPCC climate assessments and the RAINS assessments of acid rain and other pollutants conducted under LRTAP. Parson (2002) has reported a similar finding in his work on the stratospheric ozone issue. In these and other cases, it was not uncommon for 5 to 10 years to elapse between the first report of an assessment effort and the reports that finally began to be cited by decision makers as exerting a substantial influence on the policy process. During these extended periods, most of the more influential 
assessments built up extended networks of experts who learned to work with one another across disciplinary and national boundaries. They developed an increasingly rich "issue network" of that increasingly included decision makers and other interested stakeholders as active participants in the assessment process. And they developed significant organizational capacity to carry out their increasingly complex assessment activities. In general, these cumulative changes in the assessment process tended to increase the saliency, credibility and legitimacy attributed to the process by particular actors, and to increase the range of actors for whom the assessment process appeared salient, credible and legitimate enough to influence their behaviors.

What role did "learning" and critical self-reflection play in these cases of increased influence by global environmental assessments? Almost certainly, the relatively uninfluential role of ad-hoc, one-time assessments speaks to the need for time to learn the extraordinarily difficult skills of spanning boundaries across the gulfs separating disciplines, science and policy, scales, and parts of the world in ways that nurture saliency, credibility and legitimacy of the assessment process. And almost certainly, most of the longer-term assessment processes we studied did use their time to get better at "doing the job right" for many of these difficult tasks. In sodoing, however, relatively few assessment processes made formal provisions for rising above the most elementary forms of "trial-and-error" learning. As a result, few tactical complaints about the previous round of assessments were addressed, for example the reforms to increase the independence of peer review in the IPCC. In contrast, bigger strategic problems have often been ignored, (and others that many in the South see the whole structure of global environmental assessments as northern dominated in a way that ignores or marginalizes other perspectives (Biermann in Mitchell et al., forthcoming; Kandlikar and Sagar 1999). Likewise, lesson-drawing from other assessment domains remained generally rare. When done at all, it has 
tended to be of a relatively casual and uncritical nature, exchanging stories (e.g., OECD Megascience) or garnering support for processes already adopted (Parson, 2002; Siebenhuner, 2002; Eckley 1999). Finally, the global environmental assessment community has made relatively little use of independent outside evaluations of their strategic mission (Social Learning Group, 2001). The predictable result has been that many otherwise effective assessment institutions risk being trapped with structures and processes that, however appropriate when the assessment was initiated, do not keep up with the changing politics of their issues, or the changing needs of decision makers.

Fortunately, a number of partial exceptions to the generally inadequate provision for learning and self-reflection in global environmental assessments begin to suggest directions that future reforms might profitably explore. Eckley's study (in Mitchell et al., forthcoming) shows how care and sensitivity allowed the global assessment of persistent organic pollutants to draw useful lessons from earlier regional assessments of the issue without becoming trapped in inappropriate models of frames. Cash's work (in Mitchell et al., forthcoming) on assessment processes linking the science of global climate to the needs of local farmers shows how careful attention to institutions assuring feedback from users to producers can keep an assessment system learning new goals, as well as new means for achieving those goals. Parson (2002) makes an analogous case for the importance of accountability to users in his study of long-term evolution of the stratospheric ozone issue, and the contribution of assessments to it. More generally, as argued by Guston $(1994,1999)$, there is some indication that as assessments move from occasional appraisals of the implications of the science for decision making toward continuous processes for operational decision support, that institutions making provision for 
serious, binding feedback from a defined end-user community are much more likely to learn hard lessons from their failures as well as successes.

Are any of these beginnings likely to influence future assessment practice in the global environmental arena? As we wait to see, it is worth noting that one of the major new efforts launched in recent years - the Millennium Ecosystem Assessment - has adopted more formal provisions for continuous feedback and periodic independent review than virtually any of its predecessors. We therefore have an experiment in process from which all concerned with the influence of global environmental assessments have much to learn.

\section{IMPLICATIONS FOR THE STUDY OF INFORMATION AS INFLUENCE}

Do these findings regarding the role of information in global environmental affairs shed any light on the influence of information in other areas of international affairs?

We believe our research does. The emerging agenda we attempt to illuminate in this paper sits at the nexus of three recent trends in the analysis of international relations: a shift away from an exclusive focus on the state to include non-state actors, an increasing focus on the role of information and ideas in shaping international behavior, and a movement away from seeing international politics and behavior as separate and separable from domestic politics and behavior (Haas 1998; Keck and Sikkink 1998; Princen and Finger 1994). Whether one could ever have fully understood outcomes in international relations by focusing on how states used military might and economic power to pursue their interests, one certainly cannot do so today.

Information has become an important supplement to, although surely not a replacement for, more traditional and material tools of statecraft. 
Information appears to have increasing influence over outcomes in a wide array of global arenas. It has become commonplace to note how the Internet and the "Information Age" have altered international life. Transparency has been recognized as an effective means, at least at times, for altering behavior (Finel and Lord 2000). Registers of armaments have become an increasingly attractive means of reducing the threat from weapons even if states are unwilling to reduce their numbers (United Nations and Department for Disarmament Affairs 1992). The World Trade Organization has increasingly sought to develop systems that would make information regarding each country's subsidies and other non-tariff barriers as transparent as information about tariffs is. Human rights regimes have used publicity regarding violations to influence government policies even when all sides knew that no official sanctions would follow (Cohen, Hart and Kosloske 1992; Keck and Sikkink 1998). Unlike more material sources of power, information alters behavior, whether of state or non-state actors, not by directly altering deep-seated values and goals or more immediate preferences among alternatives but by more indirectly altering the beliefs actors have about what their interests are and the best ways to pursue them. Information facilitates the "enlightenment" of "enlightened self-interest." We investigate why some information enlightens while other information does not, to more carefully investigate and validate whether, when, and how information influences behavior.

Our study also supports claims that the actions of non-state actors are both the source of changes at the international level and the target of those seeking change. In communications, corporations rather than governments are increasingly taking the lead at establishing the standards by which (and thereby controlling how) information is exchanged globally (Drake 2001). In the environmental realm, scientists and epistemic communities have been shown to have considerable influence over both policy and behavior. But non-governmental actors of all 
sorts have gained important influence in a wide range of issue areas. The Campaign to Ban Landmines has become a quintessential case of non-governmental actors influencing the "high politics" of international security, and being recognized with the Nobel Peace Prize for doing so. The nongovernmental organization Transparency International, almost single-handedly, has made corruption an international issue and begun to reduce both the demands government officials make for bribes and the willingness of corporations to pay them (Richardson 2001). Global and regional environmental assessments are not merely, or even primarily, the work of governments or intergovernmental bodies but representative efforts by scientists and others, often in non-official capacities, to influence public policy.

Finally, our research demonstrates clearly the importance of understanding the local to understand the global or, as US Senator Tip O'Neill once said, "all politics is local." Robert Putnam's captivating notion of international negotiations as "two-level games" that take place as much within, as among, countries opened up considerable research into how domestic level factors influence international relations and vice versa (Putnam 1988). The work we highlight reinforces that claim. As shown throughout this volume, one cannot understand when and whether information will alter behaviors unless one examines local level decision makers. Whether those actors provide the informational inputs to assessments, participate in the process of assessment, and recognize the outputs of assessment processes as salient, credible, and legitimate are only a few of the ways in which "local level" factors are central to understanding informational influence. As information flows become increasingly global, as non-governmental actors become increasingly involved in international affairs, and as domestic and international politics become increasingly intertwined, understanding why information can completely alter an 
issue domain but can also have no influence at all becomes crucial both to scholars and practitioners. 


\section{REFERENCES}

Alcock, F. Forthcoming. "A Contrast of Assessment Failure in New England and Newfoundland" in Mitchell et. al, Global Environmental Assessments: information, institutions and influence. (In review, updates on http://environment.harvard.edu/gea/).

Andresen, Steinar, Tora Skodvin, Arild Underdal and Jorgen Wettestad. (2000). Science and politics in international environmental regimes: between integrity and involvement, New York: Manchester University Press.

Axelrod, Robert M. 1997. The complexity of cooperation: agent-based models of competition and collaboration. Princeton, N.J.: Princeton University Press.

Axelrod, Robert, and Robert O. Keohane. 1986. “Achieving cooperation under anarchy: strategies and institutions." Pp. 226-254 in Cooperation under anarchy, edited by Kenneth Oye. Princeton, NJ: Princeton University Press.

Axelrod, Robert. 1984. The evolution of cooperation. New York: Basic Books.

Baumgartner, F.R., and B. D. Jones. 1993. Agendas and Instability in American Politics. Chicago: University of Chicago Press.

Biermann, Frank. 1997. "Financing environmental policies in the south: experiences from the Multilateral Ozone Fund.” International Environmental Affairs 9:179-218.

Biermann, Frank. Forthcoming. "Whose Experts? The Role of Geographic Representation in Scientific Advisory Institutions," " in Mitchell et. al, Global Environmental Assessments: information, institutions and influence. (In review, updates on http://environment.harvard.edu/gea/).

Botcheva-Andonova, Liliana. Forthcoming. "Structure and Influence of International Assessments: Lessons from Eastern Europe,” in Mitchell et. al, Global Environmental 
Assessments: information, institutions and influence. (In review, updates on http://environment.harvard.edu/gea/).

Brown Weiss, Edith, and Harold K. Jacobson (Eds.). 1998. Engaging countries: strengthening compliance with international environmental accords. Cambridge, MA: MIT Press.

Cash, D. W. (2001). “'In order to aid in diffusing useful and practical information...': cross-scale boundary organizations and agricultural extension." Science, Technology, and Human Values 26(4): 431-453.

Cash, D. W. Forthcoming. "Mining Water, Drying Wells: Multi-Level Assessment and Decision Making for Water," in Mitchell et. al, Global Environmental Assessments: information, institutions and influence. (In review, updates on http://environment.harvard.edu/gea/).

Chayes, Abram, and Antonia Handler Chayes. 1995. The new sovereignty: compliance with international regulatory agreements. Cambridge, MA: Harvard University Press.

Checkel, Jeffrey T. 1997. "International norms and domestic politics: bridging the rationalist-constructivist divide.” European Journal of International Relations 3:473-495.

Cohen, Cynthia Price, Stuart N. Hart, and Susan M. Kosloske. 1992. “The UN Convention on the Rights of the Child: developing an information model to computerize the monitoring of treaty compliance." Human Rights Quarterly 14:216-231.

Drake, William J. 2001. “Communications.” Pp. 25-74 in Managing Global Issues: Lessons Learned, edited by P. J. Simmons and Chantal de Jonge Oudraat. Washington, DC: Carnegie Endowment for International Peace.

Eckley, Noelle. 1999. "Drawing Lessons About Science-Policy Institutions: Persistent Organic Pollutants (POPs) under the LRTAP Convention”. Belfer Center for Science and 
International Affairs (BCSIA) Discussion Paper E-99-11. Cambridge, MA: Environment and Natural Resources Program, Kennedy School of Government, Harvard University.

Eckley, Noelle. Forthcoming. "From Regional to Global Information: Assessment of Persistent Organic Pollutants (POPs)" in Mitchell et. al, Global Environmental Assessments: information, institutions and influence. (In review, updates on http://environment.harvard.edu/gea/).

Farrell, A., and S. D. VanDeveer, J. Jäger (2001) "Environmental assessments: four under-appreciated elements of design” 11 (4), pp. 311-333.

Farrell, Alex, Stacy D. VanDeveer, and Jill Jaeger. 2001. “Environmental Assessments: Four Under-Appreciated Elements of Design”. Global Environmental Change 11(4): 311-333 (2001).

Finel, Bernard I., and Kristin M. Lord (Eds.). 2000. Power and Conflict in the Age of Transparency: Palgrave Publishers.

Franz, Wendy. 1998. "Science, Skeptics, and Non-State Actors in the Greenhouse”. Belfer Center for Science and International Affairs (BCSIA) Discussion Paper E-98-18. Cambridge, MA: Environment and Natural Resources Program, Kennedy School of Government, Harvard University. (http://environment.harvard.edu/gea/pubs/e\%2D98\%2D18.html)

Fritz, Jan-Stefan. 2000. The Second Report on International Scientific Advisory Processes on the Environment and Sustainable Development. Nairobi, Kenya: Division of Early Warning and Assessment, United Nations Environment Programme.

Gieryn, T. F. (1995). Boundaries of science. Handbook of science and technology studies. S. Jasanoff and et al. Thousand Oaks, CA, Sage Publications. 
Goldring, Natalie J. 1993. Moving towards transparency: an evaluation of the United Nations register of conventional arms: British American Security Information Council.

Goldstein, Judith, and Robert O. Keohane (Eds.). 1993. Ideas and foreign policy: beliefs, institutions, and political change. Ithaca, NY: Cornell University Press.

Green, Donald P., and Ian Shapiro. 1994. Pathologies of rational choice theory: a critique of applications in political science. New Haven: Yale University Press.

Guston, D. H. (1996). "Principal-agent theory and the structure of science policy." Science and Public Policy 24(4).

Guston, D. H. (1999). "Stabilizing the boundary between politics and science: the role of the Office of Technology Transfer as a boundary organization." Social Studies of Science 29(1): $87-112$.

Guston, D. H., W. Clark, et al. (2000). Report of the Workshop on Boundary Organizations in Environmental Policy and Science, Rutgers University, the Environmental and Occupational Health Sciences Institute at Rutgers University and UMDNJ-RWJMS, and The Global Environmental Assessment Project.

Gupta, Aarti. Forthcoming. "Information as Influence in Anticipatory Governance: The Case of Biosafety," in Mitchell et. al, Global Environmental Assessments: information, institutions and influence. (In review, updates on http://environment.harvard.edu/gea/).

Haas, Peter M. 1992. "Epistemic communities and international policy coordination.” International Organization 46:1-35.

Haas, Peter M. 1998. "Compliance with EU directives: insights from international relations and comparative politics." Journal of European Public Policy 5:17-37. 
Jasanoff, S. S. (1987). “Contested boundaries in policy-relevant science.” Social Studies of Science 17: 195-230.

Kandlikar, M. and A. Sagar. 1999. "Climate Change Research and Analysis in India: An Integrated Assessment of a South-North Divide”. Global Environmental Change 9(2): 119-138.

Kates, Robert W., William C. Clark, Robert Corell, J. Michael Hall, Carlo C. Jaeger, Ian Lowe, James J. McCarthy, Hans Joachim Schellnhuber, Bert Bolin, Nancy M. Dickson, Sylvie Faucheux, Gilberto C. Gallopin, Arnulf Gruebler, Brian Huntley, Jill Jäger, Narpat S. Jodha, Roger E. Kasperson, Akin Mabogunje, Pamela Matson, Harold Mooney, Berrien Moore III, Timothy O'Riordan, and Uno Svedin. 2001. “Sustainability science.” Science 292:641-42.

Keck, Margaret E., and Kathryn Sikkink. 1998. Activists Beyond Borders: Advocacy Networks in International Politics. Ithaca: Cornell University Press.

Keohane, Robert O. 1998. "International Institutions: Can Interdependence Work?” Foreign Policy:82-96.

Keohane, Robert O., and Joseph S. Nye, Jr. 1998. "Power and Interdependence in the Information Age." Foreign Affairs 77:81-94.

Keohane, Robert O., and Joseph S. Nye. 1989. Power and interdependence: world politics in transition. Boston, MA: Little, Brown, and Co.

Keohane, Robert O., Peter M. Haas, and Marc A. Levy. 1993. "The effectiveness of international environmental institutions." Pp. 3-26 in Institutions for the earth: sources of effective international environmental protection. Cambridge, MA: MIT Press.

Kingdon, John W. 1984. Agendas, alternatives, and public policies. Boston, MA: Little, Brown and Co. 
Koremenos, Barbara, Charles Lipson, and Duncan Snidal. 2001. "Rational Designs: Explaining the Form of International Institutions." International Organization 55:1-32.

Litfin, Karen T. 1994. Ozone discourses: science and politics in global environmental cooperation. New York: Columbia University Press.

March, James G. 1988. Decisions and organizations. New York: Blackwell.

March, James. 1978. "Bounded rationality, ambiguity, and the engineering of choice." Bell Journal of Economics 9:587-608.

Martin, Lisa L. 1993. “The rational state choice of multilateralism.” Pp. 91-122 in Multilateralism matters: the theory and praxis of an institutional form, edited by John Gerard Ruggie. New York: Columbia University Press.

Miles, Edward L., Arild Underdal, Steinar Andresen, Jorgen Wettestad, Jon Birger Skjaerseth, and Elaine M. Carlin (Eds.). 2001. Environmental regime effectiveness: confronting theory with evidence. Cambridge, MA: MIT Press.

Mitchell, Ronald B. 1994. Intentional oil pollution at sea: environmental policy and treaty compliance. Cambridge, MA: MIT Press.

Mitchell, Ronald B. 1998. "Discourse and Sovereignty: Interests, Science, and Morality in the Regulation of Whaling." Global Governance 4:275-293.

Mitchell, Ronald B. 1998. "Sources of transparency: information systems in international regimes." International Studies Quarterly 42:109-130.

Mitchell, Ronald B., William C. Clark, David Cash and Frank Alcock, eds. forthcoming. Global environmental assessments: Information, institutions, and influence. (In review, updates on http://environment.harvard.edu/gea/). 
Moser, Susanne C. Forthcoming. "Climate Change and Sea-Level Rise in Maine and Hawai'i: The Changing Tides of an Issue Domain," in Mitchell et. al, Global Environmental Assessments: information, institutions and influence. (In review, updates on http://environment.harvard.edu/gea/).

Müller, Harald. 1994. “Transparency in nuclear arms: toward a nuclear weapons register." Arms Control Today 24:3-7.

Parson, Edward A. 2002. Protecting the ozone layer: Science, strategy and negotiations in the shaping of a global environmental regime. (Oxford Univ. Press, forthcoming.)

Patt, Anthony. 1998. "Separating analysis from politics: the case of acid rain in Europe." in Global Environmental Assessment Summer Workshop. Bar Harbor, ME.

Patt, Anthony. 1999. "Extreme outcomes: The strategic treatment of low probability events in scientific assessments." Risk, Decision, and Policy 4(1): 1-15.

Patt, Anthony. Forthcoming. "Trust, Respect, Patience, and Sea Surface Temperatures: Useful Climate Forecasting in Zimbabwe," in Mitchell et. al, Global Environmental Assessments: information, institutions and influence. (In review, updates on http://environment.harvard.edu/gea/).

Princen, Thomas, and Matthias Finger. 1994. Environmental NGOs in world politics: linking the local and the global. New York: Routledge.

Putnam, Robert D. 1988. "Diplomacy and domestic politics: the logic of two-level games." International Organization 42:427-460.

Richardson, Peter. 2001. “Corruption.” Pp. 75-105 in Managing Global Issues: Lessons Learned, edited by P. J. Simmons and Chantal de Jonge Oudraat. Washington, DC: Carnegie Endowment for International Peace. 
Sabatier, Paul A. 1993. "Policy change over a decade or more." Pp. 13-39 in Policy change and learning: an advocacy coalition approach, edited by Paul A. Sabatier and Hank C. Jenkins-Smith. Boulder, CO: Westview.

Schattschneider, E. E. 1975. The semisovereign people: a realist's view of democracy in America. Hinsdale, Ill.: Dryden Press.

Schelling, Thomas C. 1978. Micromotives and macrobehavior. New York: Norton. Schelling, Thomas C., and Morton Halperin. 1960/85. Strategy and arms control. Washington, DC: Pergamon-Brassey.

Shepsle, Kenneth A., and Mark S. Bonchek. 1997. Analyzing politics: rationality, behavior, and institutions. New York: W.W.Norton and Co.

Siebenhuener, Bernd. 2002. "How do Scientific Assessments Learn? A Comparative Study of the IPCC and LRTAP”. Belfer Center for Science and International Affairs (BCSIA) Discussion Paper 2002-05. Cambridge, MA: Environment and Natural Resources Program, Kennedy School of Government, Harvard University.

Social Learning Group (Ed.). 2001a. Learning to Manage Global Environmental Risks, Volume 1: A Functional Analysis of Social Responses to Climate Change, Ozone Depletion, and Acid Rain. Cambridge: MIT Press.

Social Learning Group (Ed.). 2001b. Learning to Manage Global Environmental Risks, Volume 2: A Comparative History of Social Responses to Climate Change, Ozone Depletion, and Acid Rain. Cambridge: MIT Press.

Star, S. L. and J. R. Griesemer (1989). 'Institutional ecology, 'translations' and boundary objects: amateurs and professionals in Berkeley’s Museum of Vertebrate Zoology, 1907-39.” Social Studies of Science 19(3): 387-420. 
Tesh, Sylvia N., and Bruce A. Williams. 1996. "Identity Politics, Disinterested Politics, and Environmental Justice.” Polity 18:285-305.

Torrance, Wendy E. F. Forthcoming. "Science or Salience: Building an Agenda for Climate Change," in Mitchell et. al, Global Environmental Assessments: information, institutions and influence. (In review, updates on http://environment.harvard.edu/gea/).

United Nations, and Department for Disarmament Affairs. 1992. Study on ways and means of promoting transparency in international transfers of conventional arms. New York: United Nations.

United Nations, and Department for Disarmament Affairs. 1992. Study on ways and means of promoting transparency in international transfers of conventional arms. New York: United Nations.

VanDeveer, Stacy D. Forthcoming. "Assessment Information in European Politics: East and West," in Mitchell et. al, Global Environmental Assessments: information, institutions and influence. (In review, updates on http://environment.harvard.edu/gea/).

Victor, David G., Kal Raustiala, and Eugene B. Skolnikoff (Eds.). 1998. The implementation and effectiveness of international environmental commitments. Cambridge, MA: MIT Press.

Walt, Stephen M. 1999. "Rigor or Rigor Mortis? Rational Choice and Security Studies.” International security 23:5.

Waltz, Kenneth. 1979. Theory of international politics. Reading, MA: Addison-Wesley Publishing Co.

Weiss, Carol H. 1975. "Evaluation research in the political context." in Handbook Of Evaluation Research, edited by E. S. Struening and M. Gutentag. London: Sage. 
Young, Oran R. 1992. "The effectiveness of international institutions: hard cases and critical variables.” Pp. 160-194 in Governance without government: change and order in world politics, edited by James N. Rosenau and Ernst-Otto Czempiel. New York: Cambridge University Press.

Young, Oran R. 1994. "The problem of scale in human/environment relationships." Journal of Theoretical Politics 6.

Young, Oran R. 1999. Governance in world affairs. Ithaca, NY: Cornell University Press. Young, Oran R., and Marc A. Levy. 1999. “The effectiveness of international environmental regimes." Pp. 1-32 in Effectiveness of international environmental regimes: causal connections and behavioral mechanisms, edited by Oran R. Young. Cambridge, MA: MIT Press. 


\begin{abstract}
The recognition that information matters in world affairs raises a number of questions as to when, how, and under what conditions it influences the behavior of policy actors. Despite the vast and growing array of institutions involved in collecting, analyzing, and disseminating information potentially relevant to global governance generally, and global environmental change specifically, our understanding of the role that these "information institutions" play in world affairs remains limited. This paper examines how institutions mediate the impact of scientific assessments on global environmental affairs and highlights the pathways through which information has influence on the policy and politics of environmental issues. We identify salience, credibility and legitimacy as the critical attributions that different audiences make about an assessment that determine whether they will change their thoughts, decisions, and behavior in response to it. We also outline how institutional rules regarding participation, framing, and scope and content allow knowledge systems to reach needed thresholds of salience, credibility, and legitimacy and to balance the tradeoffs and tensions among them.
\end{abstract}




\section{ANNEX 1 \\ The Global Environmental Assessment Project}

This study emerges from the Global Environmental Assessment Project (GEA). We launched the Project in 1995 as an international, interdisciplinary effort directed at understanding the role of organized efforts to bring scientific information to bear in shaping social responses to large scale environmental change. The focus of the Project was the growing number of such efforts - ranging from the periodic reports of the Intergovernmental Panel on Climate Change to the Global Biodiversity Assessment to the Millennium Ecosystem Assessment - that have been conducted in support of international policymaking over the last quarter century. Our central concern was to understand the impacts of environmental assessments on large-scale interactions between nature and society, and how changes in the conduct of those assessments could alter their impacts. We attempted to advance a common understanding of what it might mean to say that one effort to mobilize scientific information is more "effective" than another. We tried to view such issues from the perspectives of both decision makers at multiple scales and the experts who provide scientific advice. We attempted to embed our research approaches and interpretation of findings in contemporary theoretical frameworks of science studies, policy studies, and international relations. At the same time, we tried to keep our efforts grounded in reality through a series of workshops that have engaged practitioners, users, and scholars of assessment in an off-the-record dialog that lets them compare insights and experiences.

Over its five year study, the GEA Project engaged a group of more than 50 senior scholars, post-doctoral fellows, and students drawn from the natural, social, and policy sciences in an intensive program of training and research. Our series of workshops with assessment practitioners and managers engaged another 50 or so individuals. The Project produced more than 40 working papers, many of which have appeared in the peer-reviewed literature. Three synthesis volumes have emerged from the GEA Project. The Patchwork Planet: Local and Global in Environmental Politics, edited by Sheila Jasanoff and Marybeth Long, has been written for scholars concerned about the tensions between globally and locally referenced knowledge that are illuminated in environmental assessment practice. Global Environmental Assessments: Information, Institutions, and Influence, edited by William Clark, Ronald Mitchell, David Cash, and Frank Alcock is addressed to the community of scholars seeking to understand the interactions of information and institutions in structuring international affairs. Finally, The Design of Environmental Assessment Processes: Global and Regional Cases, edited by Jill Jaeger and Alex Farrell, is directed towards assessment practitioners and summarizes Project findings on how the practices of global environmental assessment can be reformed to improve their utility to decision makers. A web site for the project, at http://environment.harvard.edu/gea, provides detailed information on its participants, publications and activities.

We acknowledge with gratitude the numerous groups that have provided financial and institutional support for the Project. Initial support for the Global Environmental Assessment Project was provided by a core grant from the National Science Foundation (Award No. SBR- 
9521910) to the "Global Environmental Assessment Team." Supplemental support to the Team was provided by the National Oceanic and Atmospheric Administration, the Department of Energy, the National Aeronautics and Space Administration, the National Science Foundation, and the National Institute for Global Environmental Change. Additional support has been provided by the Department of Energy (Award No. DE-FG02-95ER62122) for the project, "Assessment Strategies for Global Environmental Change," the National Institute for Global Environmental Change (Awards No. 901214-HAR, LWT 62-123-06518) for the project "Towards Useful Integrated Assessments," the Center for Integrated Study of the Human Dimensions of Global Integrated Assessment at Carnegie Mellon University (NSF Award No. SBR-9521914) for the project "The Use of Global Environmental Assessments," the European Environment Agency, the Belfer Center for Science and International Affairs at Harvard University's Kennedy School of Government, the International Human Dimensions Programme on Global Environmental Change, Harvard's Weatherhead Center for International Affairs, Harvard's Environmental Information Center, the International Institute for Applied Systems Analysis, the German Academic Exchange Service, the Heinrich Böll Foundation in Germany, the Massachusetts Institute of Technology's Center for Environmental Initiatives, the Heinz Family Foundation, the Heinz Center for Science, Economics and the Environment, and the National Center for Environmental Decision-making Research.

A number of individuals who worked in the background of the Project to make it work also deserve our thanks. Finally, we extend our deepest thanks and admiration to J. Michael Hall, Director of the Office of Global Programs at the National Oceanic and Atmospheric Administration, whose vision, wisdom and commitment has sustained us through the GEA effort.

Program leadership: William Clark (Director), Nancy Dickson (Associate Director), Jill Jaeger, Sheila Jasanoff, Robert Keohane, and James J. McCarthy 


\section{ENDNOTES}

${ }^{1}$ This paper attempts to summarize ideas developed over five years of research by the Global Environmental Assessment project, a collaborative effort summarized in Annex 1 of this paper. Lists of participants in the project, and the individual cases studies published by the participants, are available on the project web site at http://environment.harvard.edu/gea/. A volume to include a revised version of this paper, together with a selection of cases studies done by project participants, is in preparation, with plans to publish it in 2003 as Ronald Mitchell, William Clark, David Cash and Frank Alcock, eds., Global Environmental Assessments: Information, Institutions, and Influence. Updates on this publication, and other volumes produced by the project, will be provided on the web site noted above.

We wish to thank all the research fellows and faculty involved in the GEA project for their numerous research efforts and helpful insights, and Nancy Dickson, the Associate Director of the project, for her unparalleled skill in conceiving and running international, interdisciplinary research networks. The ideas in this chapter were particularly influenced during their initial stages by collaborative work done by Robert O. Keohane, Barbara Connolly, and Ronald Mitchell on the influence of information in international institutions. We are indebted to Professors Keohane and Connolly for ideas and insights developed during that process. 